\title{
Cryopreservation of Iberian red deer (Cervus elaphus hispanicus) spermatozoa obtained by electroejaculation
}

\author{
F. Martínez-Pastor ${ }^{\mathrm{a}, *}$, F. Martínez ${ }^{\mathrm{b}}, \mathrm{M}$. Álvarez ${ }^{\mathrm{b}}$, A. Maroto-Morales ${ }^{\mathrm{c}}$, \\ O. García-Alvarez ${ }^{\text {c }}$, A.J. Soler ${ }^{\mathrm{a}}$, J.J. Garde ${ }^{\mathrm{a}}$, P. de Paz ${ }^{\mathrm{d}}$, L. Anel ${ }^{\mathrm{b}}$ \\ ${ }^{a}$ Biology of Reproduction Group, National Wildlife Research Institute (IREC), CSIC-UCLM-JCCM, \\ and Institute for Regional Development (IDR), 02071 Albacete, Spain \\ ${ }^{\mathrm{b}}$ Animal Reproduction and Obstetrics, University of León, 24071 León, Spain \\ ${ }^{\mathrm{c}}$ Regional Center of Animal Selection and Reproduction (CERSYRA), JCCM, Valdepeñas, 13300 Ciudad Real, Spain \\ ${ }^{\mathrm{d}}$ Molecular Biology, University of León, 24071 León, Spain
}

Received 30 May 2008; received in revised form 13 September 2008; accepted 14 September 2008

\begin{abstract}
We tested extenders and freezing protocols for Iberian red deer semen. Samples were obtained by electroejaculation (10 stags), and analyzed for motility (CASA), viability (propidium ioide), acrosomal (PNA-FITC) and mitochondrial status (JC-1). Samples were diluted $1+1$ in extender, cooled and adjusted for glycerol (extender with higher glycerol concentration), brought to $160 \times 10^{6} \mathrm{~mL}^{-1}$ and frozen. Four experiments were carried out, repeating sperm analysis after thawing to compare treatments. In a first experiment, seven samples were frozen using Triladyl ${ }^{\mathbb{R}}(20 \%$ egg yolk) and UL extender (Tes-Tris-fructose, $15 \%$ egg yolk, $4 \%$ glycerol). Triladyl ${ }^{\mathbb{R}}$ yielded higher motility after thawing. In a second trial, 17 samples were frozen using Triladyl ${ }^{\mathbb{R}}$, Andromed $^{\mathbb{R}}$, Bioxcell $^{\mathbb{R}}$, and UL with 8\% LDL (low-density lipoproteins). Triladyl ${ }^{\mathbb{R}}$ and Andromed ${ }^{\mathbb{R}}$ performed better than Bioxcell ${ }^{\mathbb{R}}$ on motility, and than UL-LDL on viability and acrosomal status. In a third experiment, the performance of freezing the sperm-rich ejaculate fraction versus the whole ejaculate was tested on nine samples. The sperm-rich ejaculate fraction not only rendered more motile and viable spermatozoa but also showed higher freezability (higher motile spermatozoa recovery). In a fourth experiment, we tried three modifications of the freezing protocol, for improving the freezability of low concentration samples: prior removal of seminal plasma; replacing extender (second fraction) for pure glycerol to reduce dilution; and performing only the $1+1$ dilution, not the second dilution. No differences were found, although only three samples could be used. Both Triladyl ${ }^{\mathbb{R}}$ and Andromed ${ }^{\mathbb{R}}$ were deemed appropriate for freezing Iberian red deer semen, and the rich fraction should be selected for freezing. (C) 2008 Elsevier Inc. All rights reserved.
\end{abstract}

Keywords: Sperm cryopreservation; Electroejaculation; Extenders; Red deer; Semen fractions

* Corresponding author at: Ciencia y Tecnología Agroforestal y Genética (ETSIA), Universidad de Castilla-La Mancha, Av. España s/n, 02071-Albacete, Spain. Tel.: +34 967599 200x2581;

fax: +34 967594269 .

E-mail address: Felipe.Martinez@uclm.es (F. Martínez-Pastor).

\section{Introduction}

The red deer, among other wild ruminants, is a species with an expanding utility prospect [1]. Its use as farmed species has increased notably for producing meat and velvet. In this context of domestication, semen cryopreservation, artificial insemination and other artificial reproductive techniques have been successfully 
applied [2-10]. The future development of deer livestock must be undoubtedly accompanied by the development of artificial reproductive techniques adapted for these species. First, for increasing productivity, facilitating selection of desirable traits, such as meat quality and quantity, antler size and beauty (for hunting), and for preserving, by germplasm banking, interesting subspecies or selected varieties. Moreover, most cervids have strong seasonal reproductive constraints $[4,8,11]$, thus artificial reproductive techniques represent a great improvement to their management. The task of creating specific protocols for cervids might still require further effort, because, although many techniques used in domestic livestock have been showed to work in deer [8], specific changes must be carried out for optimal cryosurvival. Indeed, even within the same genus, deer species have shown to require different protocols for sperm cryopreservation [12]. In this study, we have approached several aspects of sperm cryopreservation in the Iberian red deer (Cervus elaphus hispanicus), an important game species in the Iberian Peninsula, bred in the wild and in an increasing number of farms in Spain and Portugal (mainly for hunting, but also for meat). In the case of this subspecies, germplasm banking has and additional interest, helping to preserve the purity of the subspecies (threatened by crosses with imported red deer) and improving gene flow between game states [13].

Initially, we carried out a comparison between several commercial and self-made extenders. The composition of semen extenders is one of the most important aspects affecting the outcome of spermatozoa cryopreservation [14], and the effectiveness of extenders has been shown to vary greatly between cervid species $[8,12]$. In previous studies with Iberian red deer, we successfully cryopreserved epididymal spermatozoa using extenders based on Tes-Tris-fructose [15-18], Tris-citrate-fructose [19-22], and Triladyl ${ }^{\mathbb{R}}$ (Minitüb, Tiefenbach, Germany) [23,24]. When cryopreserving electroejaculated spermatozoa, we observed that semen obtained by electroejaculation was well cryopreserved in Tes-Tris-fructose (20\% egg yolk and $4 \%$ glycerol) [17], and we obtained good results using a Tris extender with $2.5 \%$ egg yolk and 5\% glycerol [25]. Other extenders have been tried [8]. For instance, Fukui et al. [3] used a sodium citrate/egg yolk extender with $8 \%$ glycerol, Haigh et al. [26] tested egg yolk-citrate, lowfat milk and vegetable protein extender, and Veldhuizen [27] compared sodium citrate-egg yolk, Tris-glucosecitrate, skim cow's milk-egg yolk, lactose-egg yolk and a synthetic diluent for ram semen. Although suggesting that some extenders might be superior, these studies were not conclusive. In the present study, we carried out a first experiment comparing a self-made extender (TesTris-fructose-egg yolk) with the commercial extender Trilady $l^{\mathbb{R}}$. Then, in a second experiment, we compared three commercial extenders (Triladyl ${ }^{\mathbb{R}}$, Andromed $^{\mathbb{R}}$ and Bioxcell ${ }^{\mathbb{R}}$ ) with our self-made extender supplemented with LDL (low-density lipoproteins). There is a special interest in assessing the suitability of commercial extenders for red deer spermatozoa, since farmers and service providers might prefer acquiring the extenders from specialized companies instead of producing them by themselves.

In a third experiment, we compared the performance of freezing the whole ejaculate against freezing only the sperm-rich ejaculate fraction (higher sperm concentration). Electroejaculation generally occurs in fractions, which can be collected separately, and, typically, one of the fractions has a much higher sperm concentration ([28] and own unpublished data). This "fractionated" collection is compulsory because urine contamination can occur, therefore it is a good strategy to change the collection tube between semen emissions. From a practical point of view, the best option would be collecting the whole ejaculate for cryopreservation, discarding urine-contaminated tubes and the secretion of the bulbouretral glands ("yellow" fraction [28]), therefore making use of all the spermatozoa. However, this option implies a higher dilution of the spermatozoa with seminal plasma, which may be detrimental, and we cannot discard that fractions other than the rich one have a different glandular origin or different chemical composition, decreasing the general quality of the sample.

Finally, we approached the problem of cryopreserving samples with low concentration in red deer. This objective is linked with the previous one, since ejaculates sometimes yield low concentration (especially if collected after the rut, when sperm production drops [11]). Moreover, it could be convenient to freeze the low-concentrated fractions too, for instance, for highly valuable animals. When collecting these highly diluted samples, two problems arise. Firstly, sperm concentration might be so low that further dilution in a standard cryopreservation protocol might yield semen doses too diluted for post-thawing use. Secondly, high dilution with seminal plasma might be detrimental (either because of direct effect of seminal plasma or because of higher vulnerability to the cryopreservation steps). We tested different methods for cryopreserving these samples, either by removing seminal plasma by centrifugation or by minimizing further dilution after cooling. 


\section{Materials and methods}

\subsection{Reagents and media}

All chemicals were of at least Reagent grade and were acquired from Sigma (Madrid, Spain). For fixing sperm samples, we used a glutaraldehyde solution $(2 \%$ glutaraldehyde in $146 \mathrm{mM}$ glucose, $34 \mathrm{mM}$ sodium citrate tribasic and $24 \mathrm{mM} \mathrm{NaHCO}$ ). The UL base extender was prepared from a Tes-Tris-fructose base solution $\quad(231.1 \mathrm{mmol} / \mathrm{L}$ Tes, $77.1 \mathrm{mmol} / \mathrm{L}$ Tris, $16.9 \mathrm{mmol} / \mathrm{L}$ fructose; $\mathrm{pH} 7.2,320 \mathrm{mOsm} / \mathrm{kg}$ ). The base solution was double-filtered through a cellulose acetate membrane $(0.22-\mu \mathrm{m}$ pore $)$ and was complemented with $15 \%$ egg yolk and centrifuged $(3000 \times g$, $30 \mathrm{~min}$ ), discarding the sediment. Finally, we added $4 \%$ glycerol (final concentration). A modification of the UL extender (UL-LDL) was prepared by substituting LDL (low-density lipoproteins) for egg yolk. LDL were purified in our laboratory from egg yolk following McBee and Cotterill [29], and added at a concentration of $8 \%$. The characteristics of the extenders used in this study are summarized in Table 1 .

\subsection{Animals and electroejaculation}

Samples were obtained from 10 mature Iberian red deer stags during the breeding season (mid-September) in successive years (2000-2004). Animals (2.5-7.4year-old; $168 \pm 31 \mathrm{~kg}$, mean \pm S.D.) were housed in a semi-free ranging regime at the University of CastillaLa Mancha (ETSIA, Albacete, Spain), maintained under natural daylength conditions at a latitude of $38^{\circ} 57^{\prime} \mathrm{N}$. During the experiment they lived in a meadow of $6500 \mathrm{~m}^{2}$ composed of Festuca arundinacea $(52.4 \%)$, Dactylis glomerata (28.6\%), Medicago sativa (14.3\%) and Trifolium repens (4.8\%). Fodder was based on barley, alfalfa and oats, and animals had ad libitum

Table 1

Characteristics of the extenders used in this study.

\begin{tabular}{lllll}
\hline Extender & Buffer & Sugars & Cryoprotectant $^{\mathrm{a}}$ & Glycerol \\
\hline Andromed $^{\circledR}$ & Citrate & Fructose & Soybean extract & $7 \%$ \\
Bioxcell $^{\circledR}$ & ? & ? & Soybean extract & $6.4 \%$ \\
Triladyl $^{\circledR}$ & Tris-citrate & Fructose & Egg yolk (20\%) & $6 \%$ \\
UL $^{\mathrm{c}}$ & Tes-Tris & Fructose & Egg yolk (15\%) & $4 \%$ \\
UL-LDL $^{\mathrm{c}}$ & Tes-Tris & Fructose & LDL (8\%) & $4 \%$ \\
\hline
\end{tabular}

For commercial extenders, glycerol concentration is based in previous studies [30-32].

a Except glycerol.

b Added to the commercial extender.

${ }^{c}$ Made by the authors (see composition in text).

${ }^{\mathrm{d}}$ Extracted from egg yolk. access to cereal straw and water. Animal handling and electroejaculation were performed in accordance with the Spanish Animal Protection Regulation, RD223/ 1998, which conforms to European Union Regulation $86 / 609$ and adheres to guidelines established in the Guide for Care and Use of Laboratory Animals. The University of Castilla-La Mancha (Albacete, Spain) approved the procedures.

In order to prevent variations due to multiple electroejaculations, the samples used in this study were always obtained from the first electroejaculation of the breeding season. Stags were restrained and anaesthetized with an intravenous injection of $0.75 \mathrm{mg} / \mathrm{kg}$ xylacine (Rompun ${ }^{\mathrm{B}} 2 \%$; Bayer AG, Leverkusen, Germany) and $1.5 \mathrm{mg} / \mathrm{kg}$ ketamine (Imalgene $1000^{\circledR}$; Rhone-Mérieux, Lyon, France). The rectum was cleared of faeces and the prepucial area was shaved and washed with physiological saline. Electroejaculation was carried out using a rectal probe measuring $375 \mathrm{~mm}$ length and $40 \mathrm{~mm}$ width; the length of the electrodes was $80 \mathrm{~mm}$. The probe was connected to a power source that allowed to controlling voltage and amperage. Ejaculation occurred at average values of $4.5 \mathrm{~V}$ and $90 \mathrm{~mA}$ (average time to ejaculation: $3 \mathrm{~min} 44 \mathrm{~s}$ ). Anesthesia was reversed with $0.3 \mathrm{mg} / \mathrm{kg}$ yohimbine hydrochloride (prepared at $0.9 \%$; Sigma, Madrid, Spain). The ejaculates were collected by fractions in graduated glass tubes. Sperm concentration was assessed using an hemocytometer (Bürker chamber; Brand Gmbh, Germany), after diluting the sample in a glutaraldehyde solution $(5 \mu \mathrm{L}$ of sample in $500 \mu \mathrm{L}$ of $2 \%$ glutaraldehyde solution-29 g/L glucose monohydrate, $10 \mathrm{~g} / \mathrm{L}$ sodium citrate tribasic dihydrate and $2 \mathrm{~g} / \mathrm{L}$ sodium bicarbonate), allowing to discriminate a highly concentrated (sperm-rich) fraction and several fractions of low concentration semen. We discarded the fractions suspected of urine contamination. The volume of each fraction was recorded, and the tubes were put in a water bath at $30^{\circ} \mathrm{C}$ for assessment and processing.

\subsection{Semen analysis}

Before starting the cryopreservation protocols and after thawing, samples were assessed for motility, viability, acrosomal status and mitochondrial activity. Motility was analyzed by using a CASA system (Computer Assisted Sperm Assessment). Samples were diluted down to $10-20 \times 10^{6}$ spermatozoa $\mathrm{mL}^{-1}$ in PBS (pH 7.5, $320 \mathrm{mOsm} / \mathrm{kg}$ ), and a flat $5-\mu \mathrm{L}$ drop was examined on a warming stage at $37^{\circ} \mathrm{C}$ with a phase contrast microscope (Nikon Labophot-2; negative contrast optics), coupled with a Sony XC-75CE camera. 
The software of the CASA was the Motility Analyzer v. 7.4G (Hamilton-Thorne Research ${ }^{\mathrm{TM}}$ ). We saved the following parameters for further analysis: motile spermatozoa (\%), progressive spermatozoa (\%), average path velocity $(\mu \mathrm{m} / \mathrm{s}$; VAP), straightness $(\%$; STR $)$, amplitude of the lateral movement of the head $(\mu \mathrm{m}$; ALH) and head beat cross frequency ( $\mathrm{Hz}$; BCF). Detailed explanation of these descriptors of sperm movement has been provided elsewhere [33]. At least 5 fields and 200 cells were recorded at $\times 200$, using an image acquisition rate of 25 frames/s and an acquisition time of $0.8 \mathrm{~s}$. Progressive motility was defined as the percentage of spermatozoa with VAP $>25 \mu \mathrm{m} / \mathrm{s}$ and STR $>80 \%$.

Viability and acrosomal status assessments were carried out simultaneously using fluorescent probes [16]. Samples were diluted in PBS (1/100), and stained with prodidium ioide (PI; $25 \mu \mathrm{g} / \mathrm{L}$ ) and PNA (peanut agglutinin) conjugated with FITC $\left(1 \mu \mathrm{g} \mathrm{mL}^{-1}\right)$. Then, they were kept $10 \mathrm{~min}$ in the dark before being analyzed. In a separate analysis, mitochondrial activity was assessed using the mitochondrial probe JC-1 $\left(5,5^{\prime}, 6,6^{\prime}\right.$-tetrachloro-1, $1^{\prime}, 3,3^{\prime}$-tetraethylbenzimidazolocarbocyanine iodide). Samples were stained with $15 \mu \mathrm{M} \mathrm{JC}-1$ and incubated for $30 \mathrm{~min}$ at $37^{\circ} \mathrm{C}$ in the dark. In both cases, samples were observed with an epifluorescence microscope (Nikon Optiphot; $\times 400$, $450-490 \mathrm{~nm}$ excitation filter, $510 \mathrm{~nm}$ dichroic-beam splitter, $520 \mathrm{~nm}$ barrier filter). At least 100 cells were assessed. For PI/PNA-FITC, we considered four types of spermatozoa: red (non-viable, acrosome intact), redgreen (non-viable, acrosome damaged), green (viable, acrosome damaged) and non-stained (viable; acrosome intact). For JC-1, we considered the spermatozoa with orange midpiece (JC-1 aggregates) as having high mitochondrial membrane potential $\left(\Delta \psi_{m}\right)$.

\subsection{Freezing protocols}

\subsubsection{Comparison of Triladyl ${ }^{\mathbb{R}}$ and UL extenders}

Only the sperm-rich fraction of each ejaculate was used for comparing the extenders. In a first trial, the commercial extender Triladyl ${ }^{\circledR}$ (Minitüb, Tiefenbach, Germany) was compared with the UL extender. Triladyl ${ }^{\circledR}$ was supplemented with $20 \%$ egg yolk. Seven semen samples were frozen with each of the extenders following the same protocol. Samples were split in two $15-\mathrm{mL}$ glass centrifuge tubes and diluted with an equal volume of extender $(1+1)$ at ambient temperature. The tubes were put in beakers containing $100 \mathrm{~mL}$ of water at ambient temperature and it was cooled to $5^{\circ} \mathrm{C}$ (slow cooling, $90 \mathrm{~min}$ ), and left for an equilibration time of
$2 \mathrm{~h}$. Then, the samples were diluted again with an equal volume of extender $(1+1)$ with a higher concentration of glycerol (6\% for UL and $9 \%$ for the others), in order to reach the final glycerol concentration for each extender (4\% and $6 \%$, respectively). Samples were immediately diluted down to $160 \times 10^{6} \mathrm{sperm} \mathrm{mL}^{-1}$ with the original extender (4\% glycerol for UL and $6 \%$ for the others) and left for one more hour. Semen was packed in 0.25-mL straws (IMV, L'Aigle Cedex, France) and frozen in nitrogen vapors $(4 \mathrm{~cm}$ above liquid nitrogen) for $10 \mathrm{~min}$, and transferred to liquid nitrogen, where they were kept at least for a year. Thawing was performed by dropping the straws in water at $65^{\circ} \mathrm{C}$ for $6 \mathrm{~s}$.

\subsubsection{Comparison of Triladyl ${ }^{\mathbb{R}}$, Bioxcell $^{\mathbb{R}}$,}

Andromed $^{\mathbb{R}}$ and $U L-L D L$ extenders

In a second trial, the extenders Triladyl ${ }^{\circledR}$, Bioxcell ${ }^{\mathbb{R}}$ (IMV, L'Aigle Cedex, France), Andromed ${ }^{\circledR}$ (Minitüb, Tiefenbach, Germany) and UL-LDL were compared. Bioxcell $^{\mathbb{R}}$ contained $6.4 \%$ glycerol, and Andromed $^{\mathrm{R}}$ $7 \%$ glycerol. Both extenders include soybean extract as cryoprotectant. Seventeen semen samples were frozen with each of the extenders, following the protocol described for the first trial.

\subsubsection{Cryopreservation of whole ejaculates versus} the sperm-rich ejaculate fraction

Nine electroejaculations were performed. Part of the sperm-rich fraction of each ejaculate was reserved for freezing. The rest of the sperm-rich fraction was mixed proportionately (weighted means based on volume) with the low-concentration fractions, thus mimicking the result of a non-fractioned collection. Both samples were extender with Triladyl ${ }^{\circledR}$ and frozen following the same protocol used for the extender comparison (Section 2.4.1).

\subsubsection{Improvement of the extension protocol for low concentration samples}

This experiment was carried out using three lowconcentration ejaculates. Each ejaculate was split among four $15-\mathrm{mL}$ glass tubes, and the first tube was submitted to the standard cryopreservation protocol (Section 2.4.1; using Triladyl ${ }^{\mathbb{R}}$ ), while the other three were submitted to modifications of this protocol. These modifications were designed with the purpose of while improving the quality of the ejaculates frozen as a whole. In the first modification (Centrifugation protocol), the tube was centrifuged at $600 \times g$ for $6 \mathrm{~min}$ and the seminal plasma was removed. The volume of the reducing the dilution of low-concentration samples, 
Table 2

Initial semen quality (for each experiment).

\begin{tabular}{|c|c|c|c|c|c|}
\hline \multirow[t]{2}{*}{ Parameters $^{a}$} & \multirow[t]{2}{*}{$\begin{array}{l}\text { Comparison } \\
\text { Triladyl }{ }^{\circledR} \text { vs. UL }\end{array}$} & \multirow{2}{*}{$\begin{array}{l}\text { Comparison } \\
{\text { Triladyl }{ }^{\circledR} \text { vs. }} \text { Andromed }^{\mathbb{R}} \text { vs. } \\
\text { Bioxcell }^{\mathbb{R}} \text { vs. } \\
\text { UL-LDL }\end{array}$} & \multicolumn{2}{|c|}{$\begin{array}{l}\text { Comparison whole ejaculate vs. } \\
\text { sperm-rich fraction }\end{array}$} & \multirow{2}{*}{$\begin{array}{l}\text { Protocols for } \\
\text { low-concentration } \\
\text { samples }\end{array}$} \\
\hline & & & Whole & Rich & \\
\hline Number of samples & 7 & 17 & 9 & 9 & 3 \\
\hline Concentration $\left(10^{6} \mathrm{~mL}^{-1}\right)$ & $1583 \pm 199$ & $1234 \pm 159$ & $402 \pm 83$ & $1107 \pm 176$ & $609 \pm 353$ \\
\hline Motile $(\%)$ & $88.3 \pm 2.5$ & $85.6 \pm 1.9$ & $77.0 \pm 6.3$ & $86.4 \pm 3.7$ & $82.2 \pm 3.1$ \\
\hline Progressive (\%) & $59.1 \pm 3.9$ & $64.0 \pm 2.2$ & $61.7 \pm 5.6$ & $64.4 \pm 2.9$ & $69.1 \pm 2.2$ \\
\hline $\operatorname{VAP}(\mu \mathrm{m} / \mathrm{s})$ & $110.6 \pm 8.1$ & $113.3 \pm 5.2$ & $108.8 \pm 10.9$ & $110.6 \pm 11.6$ & $122.6 \pm 15.3$ \\
\hline STR $(\%)$ & $74.3 \pm 3.9$ & $80.0 \pm 1.7$ & $85.3 \pm 4.6$ & $86.3 \pm 1.5$ & $86.0 \pm 2.1$ \\
\hline $\mathrm{ALH}(\mu \mathrm{m})$ & $5.1 \pm 0.4$ & $4.4 \pm 0.2$ & $3.8 \pm 0.3$ & $3.5 \pm 0.4$ & $3.6 \pm 0.1$ \\
\hline $\mathrm{BCF}(\mathrm{Hz})$ & $9.4 \pm 0.7$ & $10.0 \pm 0.4$ & $10.3 \pm 1.1$ & $10.7 \pm 0.9$ & $9.8 \pm 0.4$ \\
\hline Viability (\%) & $80.3 \pm 2.0$ & $74.0 \pm 5.3$ & $65.0 \pm 8.2$ & $82.5 \pm 2.2$ & $64.2 \pm 9.7$ \\
\hline Acrosomes (\%) & $91.7 \pm 1.2$ & $95.0 \pm 1.2$ & $88.8 \pm 5.1$ & $95.5 \pm 1.7$ & $96.2 \pm 1.1$ \\
\hline Mitochondria (\%) & $\mathrm{b}$ & $66.5 \pm 10.6$ & $44.9 \pm 12.8$ & $66.5 \pm 10.6$ & $\mathrm{~b}$ \\
\hline
\end{tabular}

Values are mean \pm S.E.M..

a VAP: average path velocity; STR: straightness; ALH: amplitude of the lateral movement of the head; BCF: head beat frequency; Viability: propidium ioide negative spermatozoa (undamaged plasmalemma); Acrosomes: PNA-FITC negative spermatozoa (undamaged acrosomal cap); Mitochondria: spermatozoa with high mitochondrial membrane potential (JC-1 stain).

${ }^{\mathrm{b}}$ Not estimated.

pellet was estimated and it was diluted with an equal volume of Triladyl $^{\circledR}$, cooled slowly and further processed following the standard protocol. The semen in the third tube (Glycerol protocol) was directly diluted with the same volume of extender and cooled slowly to $5{ }^{\circ} \mathrm{C}$. After the equilibration step, the final concentration of glycerol was achieved by adding pure glycerol directly to the semen (the adequate volume of glycerol was calculated in each case), and more extender was added only if necessary to lower the sperm concentration of the sample (final concentration: $160 \times 10^{6}$ $\mathrm{mL}^{-1}$ ). The fourth tube was processed just like in the Glycerol protocol, but neither extender nor pure glycerol were added after cooling (Direct protocol). Thus, the problem of working with low-sperm concentrations, frequent when collecting the whole ejaculate, was worked out by three manners: increasing sperm concentration by removing seminal plasma (Centrifuged); removing one of the dilution steps by adding glycerol directly (Glycerol) instead of adding Tr; and removing the dilution steps after cooling, without correcting glycerol concentration (Direct).

\subsection{Statistical analysis}

The $\mathrm{R}$ statistical environment [34] was used to perform statistical analysis. Our hypotheses were tested by using mixed-effects linear models after transforming the data (arc sine for percentages and decimal logarithm for other). When necessary, pairwise comparisons were carried out using contrasts and Holm's correction for multiple comparisons. Numeric results are expressed as mean \pm S.E.M.

\section{Results}

Semen quality before each experiment is showed in Table 2 for reference. In the third experiment (comparison of the whole ejaculate and the sperm-rich ejaculate fraction), the sperm-rich ejaculate fraction yielded higher quality, but only differed significantly for viability $(P=0.046)$.

In the comparison between Triladyl ${ }^{\mathbb{R}}$ and UL, both extenders showed similar post-thawing results. Only motile spermatozoa $(73.2 \pm 9.1 \%$ vs. $59.8 \pm 9.0 \%$; $P=0.041)$ and ALH $(4.4 \pm 0.2 \mu \mathrm{m}$ vs. $3.9 \pm 0.3 \mu \mathrm{m}$; $P=0.009$ ) were significantly higher for Triladyl ${ }^{\circledR}$. The rest of the CASA parameters (progressive spermatozoa: $42.2 \pm 4.8 \%$ vs. $37.2 \pm 6.7$; VAP: $64.4 \pm 2.5 \mu \mathrm{m} / \mathrm{s}$ vs. $58.3 \pm 3.1 \mu \mathrm{m} / \mathrm{s}$; STR: $66.2 \pm 14.6 \%$ vs. $82 \pm 3.1 \%$; BCF: $10.7 \pm 0.9 \mathrm{~Hz}$ vs. $13.5 \pm 1.8 \mathrm{~Hz}$ ) and the fluorescence parameters (viability: $56.1 \pm 6.6 \%$ vs. $56.7 \pm 6.9 \%$; acrosomes: $96.3 \pm 3.1 \%$ vs. $89.3 \pm 5.9 \%$ ) did not differ significantly (numbers are Triladyl ${ }^{\circledR}$ vs. UL).

According to these results, Triladyl ${ }^{\circledR}$ was used as the standard extender for the rest of the experiments. Results of the comparison between Triladyl ${ }^{\circledR}$, Andromed $^{\circledR}$, Bioxcell ${ }^{\circledR}$ and UL-LDL are summarized in Table 3. UL-LDL could not be analyzed by CASA 
Table 3

Post-thawing semen quality using the extenders Triladyl ${ }^{\mathbb{R}}$, Andromed $^{\mathbb{R}}$, Bioxcell ${ }^{\mathbb{R}}$ and UL-LDL.

\begin{tabular}{llll}
\hline Parameters $^{\mathrm{a}}$ & Triladyl $^{\circledR}$ & Andromed $^{\circledR}$ & Bioxcell $^{\circledR}$ \\
\hline Motile (\%) & $56.6 \pm 6.2^{\mathrm{a}}$ & $47.9 \pm 7.0^{\mathrm{ab}}$ & $39.1 \pm 8.4^{\mathrm{b}}$ \\
Progressive (\%) & $26.7 \pm 4.0$ & $23.9 \pm 4.7$ & $28 \pm 6.7$ \\
VAP $(\mu \mathrm{m} / \mathrm{s})$ & $70.7 \pm 6.2$ & $70 \pm 4.7$ & $67 \pm 7.5$ \\
STR $(\%)$ & $54.6 \pm 5.0^{\mathrm{a}}$ & $53.8 \pm 2.8^{\mathrm{a}}$ & $81.1 \pm 5.2^{\mathrm{b}}$ \\
ALH $(\mu \mathrm{m})$ & $3.2 \pm 0.2^{\mathrm{a}}$ & $3.2 \pm 0.2^{\mathrm{a}}$ & $2.2 \pm 0.2^{\mathrm{b}}$ \\
BCF $(\mathrm{Hz})$ & $7.7 \pm 0.6$ & $7.2 \pm 0.4$ & $9.3 \pm 0.8$ \\
Viability $(\%)$ & $52.0 \pm 3.2^{\mathrm{a}}$ & $48.2 \pm 5.6^{\mathrm{ab}}$ & $42.7 \pm 6.6^{\mathrm{ab}}$ \\
Acrosomes $(\%)$ & $78.4 \pm 3.4^{\mathrm{ab}}$ & $86.5 \pm 3.7^{\mathrm{a}}$ & $78.5 \pm 5.8^{\mathrm{ab}}$ \\
Mitochondria $(\%)$ & $42.0 \pm 6.6$ & $39.7 \pm 5.5$ & $51.0 \pm 12.1$
\end{tabular}

Values are mean \pm S.E.M. of 17 semen samples. Different superscripts show significations at $P<0.05$ between extenders.

${ }^{a}$ VAP: average path velocity; STR: straightness; ALH: amplitude of the lateral movement of the head ;BCF: head beat frequency; Viability: propidium ioide negative spermatozoa (undamaged plasmalemma); Acrosomes: PNA-FITC negative spermatozoa (undamaged acrosomal cap); Mitochondria: spermatozoa with high mitochondrial membrane potential JC-1 stain).

${ }^{\mathrm{b}}$ CASA could not be used, see text.

because of cloudiness in the sample. Thus, motility was assessed subjectively for Triladyl ${ }^{\mathbb{R}}(59.5 \pm 5.5 \%)$ and UL-LDL $(45.0 \pm 5.0 \%)$, not obtaining significant differences. The CASA analysis showed few differences between Triladyl ${ }^{\mathbb{R}}$ and Andromed ${ }^{\mathbb{R}}$, but freezing in Bioxcell ${ }^{\mathbb{R}}$ resulted in less motile spermatozoa and increased linearity (higher STR and lower ALH). Triladyl ${ }^{\circledR}$ yielded the higher post-thawing viability, whereas Andromed ${ }^{\mathbb{R}}$ better preserved acrosomes, being both significantly different from UL-LDL. Moreover, recalculating the percentage of acrosome-intact spermatozoa to consider only viable spermatozoa (not showed in Table 3), UL-LDL rendered a significantly lower proportion of intact acrosomes than any other extender $(97.3 \pm 0.5 \%$ vs. $99.3 \pm 0.3 \%, P<0.01)$. Although the percentage of spermatozoa with high mitochondrial membrane potential did not show differences between extenders, the dispersion of the data was dramatically larger for UL-LDL (interquartile range: 64.6) than for the other the extenders (interquartile range: 18.0), and we cannot discard that the presence of LDL particles in the extender could have interfered with the technique.

Considering experiment 3 , the cryopreservation of the whole ejaculate yielded semen doses of lower postthaw quality than when using only the sperm-rich ejaculate fraction. Table 4 shows that the post-thawing percentages of motile $(P=0.009)$ and viable spermatozoa $(P=0.028)$ were lower when using the whole ejaculate. Sperm velocity, straightness and other CASA parameters were similar, as well as the proportion of spermatozoa with intact acrosomes and active mitochondria. In this experiment, two semen samples were defined initially (that is, the sperm-rich fraction and the "whole" ejaculate), with different pre-freezing characteristics (Table 2). Therefore, we also analyzed the

Table 4

Post-thawing semen quality of the whole semen sample and the sperm-rich ejaculate fraction.

\begin{tabular}{lll}
\hline Parameters $^{\mathrm{a}}$ & Whole & Rich \\
\hline Motile $(\%)$ & $29.4 \pm 10.3^{\mathrm{a}}\left(29.7 \pm 9.9^{\mathrm{a}}\right)$ & $57.6 \pm 10.1^{\mathrm{b}}\left(61.6 \pm 10.7^{\mathrm{b}}\right)$ \\
Progressive $(\%)$ & $17.7 \pm 7.1(21.7 \pm 8.7)$ & $28.3 \pm 8.3(41.9 \pm 11.2)$ \\
VAP $(\mu \mathrm{m} / \mathrm{s})$ & $59.8 \pm 3.5(51.3 \pm 8.3)$ & $53.8 \pm 7.2(52.8 \pm 10.7)$ \\
STR $(\%)$ & $69.3 \pm 8.1(79 \pm 8.6)$ & $57.3 \pm 9.5(67.2 \pm 12)$ \\
ALH $(\mu \mathrm{m})$ & $2.8 \pm 0.3(69.5 \pm 10.8)$ & $2.8 \pm 0.2(60.4 \pm 7.7)$ \\
BCF $(\mathrm{Hz})$ & $9.4 \pm 2.3(99.2 \pm 24.1)$ & $7.5 \pm 1.1(70.7 \pm 10.1)$ \\
Viability $(\%)$ & $36 \pm 4.2^{\mathrm{a}}(59.9 \pm 7.4)$ & $50.2 \pm 3.7^{\mathrm{b}}(61.6 \pm 4.5)$ \\
Acrosomes $(\%)$ & $74.7 \pm 4(80.8 \pm 3.4)$ & $79.6 \pm 2.7(83.2 \pm 2.4)$ \\
Mitochondria $(\%)$ & $44 \pm 5.7(68.4 \pm 10.7)$ & $46 \pm 10.8(68.6 \pm 20.6)$ \\
\hline
\end{tabular}

Numbers between parentheses are recovery rates (relation among post-thawing and initial values). Values are mean \pm S.E.M. of nine semen samples. Different superscripts show significations at $P<0.05$ between fractions.

a VAP: average path velocity; STR: straightness; ALH: amplitude of the lateral movement of the head; BCF: head beat frequency; Viability: propidium ioide negative spermatozoa (undamaged plasmalemma); Acrosomes: PNA-FITC negative spermatozoa (undamaged acrosomal cap); Mitochondria: spermatozoa with high mitochondrial membrane potential (JC-1 stain). 
Table 5

Post-thawing semen quality for the three extension protocols for low-concentration samples.

\begin{tabular}{|c|c|c|c|c|}
\hline Parameters $^{a}$ & Standard ${ }^{\mathrm{b}}$ & Centrifuged $^{\mathrm{b}}$ & Glycerol $^{b}$ & Direct $^{b}$ \\
\hline Motile (\%) & $52 \pm 4.2$ & $53.3 \pm 6.9$ & $47.3 \pm 8.4$ & $58.3 \pm 6.7$ \\
\hline Progressive (\%) & $24.3 \pm 2.3$ & $26.7 \pm 3.3$ & $31 \pm 7.5$ & $35.3 \pm 6.4$ \\
\hline $\operatorname{VAP}(\mu \mathrm{m} / \mathrm{s})$ & $86 \pm 10.6$ & $85.7 \pm 5.4$ & $89.3 \pm 14.4$ & $83 \pm 8.1$ \\
\hline STR $(\%)$ & $53.7 \pm 3.5$ & $53.7 \pm 2.8$ & $60 \pm 3.6$ & $58.7 \pm 2.2$ \\
\hline $\mathrm{ALH}(\mu \mathrm{m})$ & $4 \pm 0.4$ & $4.2 \pm 0.1$ & $3.9 \pm 0.4$ & $3.8 \pm 0.2$ \\
\hline $\mathrm{BCF}(\mathrm{Hz})$ & $7.1 \pm 0.1$ & $7.8 \pm 0.2$ & $8 \pm 0.7$ & $8.1 \pm 0.7$ \\
\hline Viability (\%) & $51.1 \pm 4.3$ & $48.4 \pm 2.3$ & $52.8 \pm 5.4$ & $57.6 \pm 6$ \\
\hline Acrosomes $(\%)$ & $75.8 \pm 6.4$ & $69.8 \pm 8.1$ & $73.1 \pm 7.8$ & $71 \pm 9.9$ \\
\hline Mitochondria (\%) & $57.9 \pm 22.5$ & $64 \pm 14.5$ & $63.8 \pm 11.7$ & $44.7 \pm 18.4$ \\
\hline
\end{tabular}

Values are mean \pm S.E.M. of three semen samples. No significant differences were found between protocols.

a VAP: average path velocity; STR: straightness; ALH: amplitude of the lateral movement of the head; BCF: head beat frequency; Viability: propidium ioide negative spermatozoa (undamaged plasmalemma); Acrosomes: PNA-FITC negative spermatozoa (undamaged acrosomal cap); Mitochondria: spermatozoa with high mitochondrial membrane potential (JC-1 stain).

b Standard: not modified protocol; Centrifuged: seminal plasma was mostly removed by centrifugation and spermatozoa were frozen following the standard protocol; Glycerol: semen was diluted $1+1$ with extender and pure glycerol was added after cooling, to reach final concentration (instead of adding Triladyl ${ }^{\circledR}$ 9\% glycerol); Direct: semen was diluted $1+1$ and no further dilution or glycerol adjustments were done.

recovery rate of each parameter (value after thawing/ pre-freezing value). Rates differed significantly regarding the recovery of motile spermatozoa $(P=0.014)$.

The protocols for enhancing the cryopreservation of low-concentration samples did not differ significantly in any post-thawing parameter (Table 5). The postthawing values were higher than those showed in the comparison of sperm-rich ejaculate fraction and whole ejaculate, because these experiments were carried out in different years, and sperm characteristics differed noticeably.

\section{Discussion}

The selection of adequate extenders and freezing protocols is a fundamental step for the consolidation of artificial reproductive programs in any species. Despite of the importance of deer breeding business, there has been relatively little research on this topic, possibly because procedures used for domestic ruminants or early established protocols have worked well enough for commercial use. Most studies have focused in a reduced number of extenders, mainly based in citrate or Tris-citrate buffers, and glycerol and egg yolk as cryoprotectants [8]. Only few studies have tried combinations of different buffers, sugars or cryoprotectants [26,27], and results mostly suggested that a "classical" citrate/Tris-citrate buffer with glycerol and egg yolk might be the most adequate for red deer and other cervid species. The main objective of this study is to contribute with new information in the topic that may help to advance the development of sperm cryopreservation in deers. Our results must be interpreted considering the relatively limited number of samples available (considering the species and the added difficulty for obtaining material for research), and that observed differences between treatments may reflect differently in fertility. Therefore, this should be a starting point for considering the use of the extenders and protocols showed here, in order to improve them or test them in larger experiments, including fertility assays (either in vivo or in vitro assays [35]).

One of the objectives of the present study was to test several commercial and self-made extenders. In a first step we compared UL and Triladyl ${ }^{\mathbb{R}}$. Triladyl ${ }^{\mathbb{R}}$ has been used in wild ruminants previously, for cryopreservation of gazelle semen [30], Axis axis semen [36], and red deer and fallow deer epididymal spermatozoa [37]. Moreover, we previously have successfully frozen epididymal spermatozoa from red deer using this extender $[6,23,38]$. Here, using ejaculated semen, we have shown that this extender seemed to be slightly superior to our own UL extender, rendering higher postthawing motility. Interestingly, in a previous study using the UL extender [17], we showed that, for ejaculated semen from red deer, $4 \%$ glycerol was superior to $8 \%$. UL contained $4 \%$ glycerol, whereas Triladyl ${ }^{\mathbb{R}}$ contained $6 \%$. This do not necessarily contradict our previous study, since: (a) we did not test UL with $6 \%$ glycerol; (b) glycerol effect often depends on the extender composition (Triladyl ${ }^{\circledR}$ exact composition was unknown), therefore a higher glycerol concentration might be effective in Triladyl ${ }^{\mathbb{R}}$, but not in UL; (c) we showed that differences due to glycerol concentration were not dramatic, proposing that red deer spermatozoa might present a broad tolerance for this cryoprotectant. 
Therefore, the effect observed in the present study might be due to other components of Triladyl ${ }^{\circledR}$, and not to differences on glycerol concentration.

We have tested Andromed ${ }^{\circledR}$, Bioxcell ${ }^{\circledR}$ and an LDLbased extender for the first time on red deer semen. The interest of Andromed ${ }^{\mathbb{R}}$ and Bioxcell ${ }^{\mathbb{R}}$ is that they are free of animal ingredients, which is becoming a widespread recommendation [39]. Interestingly, Andromed ${ }^{\mathbb{R}}$ and Trilady $1{ }^{\mathbb{R}}$ presented little differences, and the former seemed to be the most appropriate for preserving acrosomal integrity, which has been remarked previously [40]. Although Andromed ${ }^{\mathbb{R}}$ has not always performed well in ruminants [41], Fukui et al. [51] recently reported that Andromed ${ }^{\mathbb{R}}$ rendered fertility results comparable to egg yolk extenders, after intrauterine insemination of sheeps. This makes Andromed ${ }^{\circledR}$ a promising option for further research on red deer. Contrary, Bioxcell ${ }^{\mathbb{R}}$ performance was poor, yielding less motile spermatozoa post-thawing. Moreover, the motility pattern was also modified, comparing to Triladyl ${ }^{\mathbb{R}}$ and Andromed ${ }^{\mathbb{R}}$ (higher straightness and lower ALH), which might reflect underlying changes. Although viability was not significantly different from the other extenders, a trend appeared when compared to Triladyl ${ }^{\mathbb{R}}(P=0.096)$. Therefore, this extender might not be as appropriate as Andromed $^{\mathbb{R}}$ for deer. Bioxcell ${ }^{\circledR}$ might be inferior to Triladyl ${ }^{\circledR}$ on fallow deer semen too [37](this study was not conclusive, though). Like Triladyl ${ }^{\circledR}$, both Andromed $^{\circledR}$ and Bioxcell ${ }^{\circledR}$ had a higher glycerol concentration than UL. As mentioned previously, it is possible that the effect of the glycerol depends on other components of the extender, thus Andromed ${ }^{\mathbb{R}}$ might render better results with a higher glycerol concentration. Nevertheless, since the exact extender composition is not readily available from the manufacturers, a thorough interpretation of the results is just tentative.

When using LDL as cryoprotectant, the viability and acrosomal status were noticeably compromised. LDL are supposed to constitute the cryoprotective fraction of egg yolk [43], thus the interest in using them directly as cryoprotectants. Although the results obtained in this study are little promising, we have to consider that LDL were used at a concentration judged adequate for ram semen, and that higher concentrations seemed to be detrimental in that species (unpublished data). It is possible that LDL concentration was highly speciesdependent, and that use of LDL should be approached in red deer by testing several concentrations in the first place.

We have showed that, while performing electroejaculation, it would be advisable to save the sperm-rich ejaculate fraction separately and use it for cryopreservation, discarding the rest of the fractions. [44], using artificial vagina, showed that the presence of a spermrich ejaculate fraction ("white") was typical of the peak of the mating period in red deer (September to November). Before and after this period, a lowconcentration fraction ("grey") appeared, and it was typical of the rest of the breeding season. It is possible that electroejaculation induced the emission of a higher quantity of seminal plasma, reflected in the collection of highly diluted fractions, which would not had happened in natural service (since we performed our collection during the rut). Previous studies have shown that the composition of seminal plasma in small ruminants varies seasonally and depends on the differential activation of the glands of the reproductive tract [4547]. Nunes et al. [45] showed that seminal plasma in the non-breeding season had a more detrimental effect on goat semen, due to its different composition. Thus, the excess of seminal plasma induced by electroejaculation might also result from forcing secretions that might be detrimental for spermatozoa. We have observed that spermatozoa obtained by electroejaculation (even from the sperm-rich ejaculate fraction only) seem to lose quality quickly if incubated in media without egg yolk (unpublished data), therefore even simply an excess of seminal plasma could have a negative role. In the present study, some differences in sperm quality were already evident before cryopreservation, which might explain some post-thawing differences. Furthermore, the recovery rate of motile spermatozoa showed that sperm freezability could be negatively affected by processing the whole ejaculate, instead of the spermrich ejaculate fraction.

In our third experiment, we tested three protocols for improving the cryopreservation of low-concentrated samples, with the aim of overcoming their lesser quality and improving the concentration of the frozen doses. It must be taken into account that sperm concentration drop after the rut $[11,44]$, and that in some cases it would be interesting to cryopreserve not only the sperm-rich ejaculate fraction, but also the lowconcentrated fractions collected during the electroejaculation session. Moreover, electroejaculation sometimes yields only low-concentrated fractions, thus the only option is working with highly diluted spermatozoa. Unfortunately, we were limited to three samples for this experiment, which lowered the power of the statistics in detecting significant differences. Nevertheless, we could appreciate that differences were indeed low enough for discarding any dramatic improvement by any of the protocols. From a practical point of view, it is 
interesting that the protocol requiring less handling and dilution of the sample, the Direct protocol, gave results similar to the others. We must take into account that the Direct protocol produced samples with only half the glycerol concentration (3-4\%), supporting our previous suggestion that red deer spermatozoa might be adequately cryopreserved using a wide range for the glycerol concentration, and that the optimal one for electroejaculated spermatozoa might be relatively low (around 4\%) [17]. Nevertheless, this reasoning implies that the Direct protocol might not be adequate if the glycerol concentration of the original extender was low (or if the spermatozoa did not have a good tolerance to different glycerol concentrations, as it might be the case with other cervids). Further research is necessary for confirming our results, clarifying possible differences between protocols, and for trying other protocols for cryopreserving these low-concentrated samples, improving freezability while achieving an adequate sperm concentration in cryopreserved doses.

In these studies we found a great variability between individuals, both regarding initial semen quality and semen freezability. Although we could not study it deeply, it was evident that some samples might have benefitted from individual adjustments of the extender or protocol. Wild species or, as this is the case, recently domesticated species, present an individual variability much higher than other domesticated species [48]. For instance, a recent study in Gazella cuvieri showed that extender choice seemed to vary depending on male [49], being most samples better cryopreserved on a raffinosebased medium, whereas several males rendered better results when a fructose-based medium was used. In fact, this variability could be an advantage in many studies that require high between-male variability. Moreover, domestic species might have lost much variability, and wild or recently domesticated species could be used for that purpose [50]. Focusing on the development of cryopreservation protocols for red deer, the information given by studies like the present one must be considered taking into account that a high variability on sperm quality and freezability may exist. Besides developing standardized protocols, parallel research should be carried out on customizing protocols for individuals with low freezability or other special semen traits, already being done in other species [?].

In conclusion, in this study the commercial extenders Triladyl ${ }^{\circledR}$ (with $20 \%$ egg yolk) and Andromed $^{\circledR}$ rendered the best results and might be candidates for use in the cryopreservation of Iberian red deer semen. It is important to highlight that Andromed ${ }^{\circledR}$ does not contain animal-derived ingredients, therefore standing as an interesting option for freezing deer semen. We have shown that these two extenders can be used in red deer with good results, and this information might be useful for the application of semen cryopreservation in farms, where the use of commercial extenders could be convenient. Nevertheless, further studies are necessary for improving these extenders. LDL performed deficiently, but its use must not be discarded until thoroughly tested. It might be important to refer to studies on epididymal spermatozoa on red deer. Regarding extender research on red deer, although epididymal spermatozoa differ in some aspects from ejaculated ones [52], and optimal cryopreservation protocols might differ [17], ample experimental data have been published in the last years on this kind of samples [6,7,15,17-23,37,38,53,54], which might be used as a starting point for studies on ejaculated spermatozoa in this or related species. We also found that it might be advisable to collect semen fractions separately during electroejaculation, and cryopreserve only the sperm-rich ejaculate fraction, since quality and freezability appear to diminish when the electroejaculate is managed as a whole. The three protocols designed to attempt an improvement in the cryopreservation of low-concentration ejaculates did not reflect any difference, but this experiment was limited by low sample size. Therefore, the development of specific protocols for these special cases must be continued in future research.

\section{Acknowledgements}

This study has been supported in part by Junta de Castilla y León (AB29) and Junta de Castilla-La Mancha (PREG-01-0006). The authors thank Camino Guerra and Patri Martínez for helping process the samples. Felipe Martínez-Pastor was supported by the Juan de la Cierva program (Spanish Ministry of Education and Science). Olga García-Álvarez and Alejandro Maroto-Morales were recipients of scholarships from INIA and Junta de Comunidades de CastillaLa Mancha (Spain), respectively.

\section{References}

[1] Fletcher TJ. Farmed deer: new domestic animals defined by controlled breeding. Reprod Fertil Dev 2001;13(7-8):511-6.

[2] Fennessy P, Mackintosh C, Shackell G. Artificial insemination of farmed red deer (Cervus elaphus). Animal Production 1990;51(3):613-21.

[3] Fukui Y, McGowan LT, James RW, Asher GW, Tervit HR. Effects of culture duration and time of gonadotropin addition

\section{0}


on in vitro maturation and fertilization of red deer (Cervus elaphus) oocytes. Theriogenology 1991;35(3):499-512.

[4] Asher GW, Monfort SL, Wemmer C. Comparative reproductive function in cervids: implications for management of farm and zoo populations. J Reprod Fertil Suppl 1999;54:143-56.

[5] Asher G, Fisher M, Fennessy P, Mackintosh C, Jabbour H, Morrow C. Oestrous synchronization, semen collection and artificial insemination of farmed red deer (Cervus elaphus) and fallow deer (Dama dama). Anim Reprod Sci 1993;33(14):241-65.

[6] Malo A, Garde J, Soler A, García A, Gomendio M, Roldan E. Male fertility in natural populations of red deer is determined by sperm velocity and the proportion of normal spermatozoa. Biol Reprod 2005;72(4):822-9.

[7] Zomborszky Z, Zubor T, Toth J, Horn P. Sperm collection from shot red deer stags (Cervus elaphus) and the utilisation of sperm frozen and subsequently thawed. Acta Vet Hung 1999;47(2): 263-70.

[8] Asher G, Berg D, Evans G, Salamon S, Maxwell W. Storage of semen and artificial insemination in deer. Anim Reprod Sci 2000;62(1-3):195-211.

[9] Gordon I. Controlled reproduction in deer. In: Controlled reproduction in horses, deer and camelids, Controlled reproduction in farm animals, vol. 41st ed., Oxon, UK: CAB International; 1997 p. $168-88$.

[10] Berg DK, Asher GW. New developments reproductive technologies in deer. Theriogenology 2003;59(1):189-205.

[11] Martinez-Pastor F, Guerra C, Kaabi M, Garcia-Macias V, de Paz $\mathrm{P}$, Alvarez M, et al. Season effect on genitalia and epididymal sperm from Iberian red deer, roe deer and Cantabrian chamois. Theriogenology 2005;63(7):1857-75.

[12] Cheng FP, Wu JT, Chan JP, Wang JS, Fung HP, Colenbrander B, et al. The effect of different extenders on post-thaw sperm survival, acrosomal integrity and longevity in cryopreserved semen of Formosan Sika deer and Formosan Sambar deer. Theriogenology 2004;61(9):1605-16.

[13] Garde J, Martinez-Pastor F, Gomendio M, Malo A, Soler A, Fernandez-Santos M, et al. The application of reproductive technologies to natural populations of red deer. Reprod Domest Anim 2006;41(Suppl. 2):93-102.

[14] Yoshida M, Forsberg M, Greve T, Gustafsson H, Katila T, Kindahl $\mathrm{H}$, et al. Conservation of sperms: current status and new trends. Anim Reprod Sci 2000;60-61:349-55.

[15] Martinez-Pastor F, Garcia-Macias V, Alvarez M, Herraez P, Anel L, de Paz P. Sperm subpopulations in Iberian red deer epididymal sperm and their changes through the cryopreservation process. Biol Reprod 2005;72(2):316-27.

[16] Martinez-Pastor F, Garcia-Macias V, Alvarez M, Chamorro C, Herraez P, de Paz P, et al. Comparison of two methods for obtaining spermatozoa from the cauda epididymis of Iberian red deer. Theriogenology 2006;65(3):471-85.

[17] Martinez-Pastor F, Martinez F, Garcia-Macias V, Esteso M, Anel E, Fernandez-Santos M, et al. A pilot study on post-thawing quality of Iberian red deer spermatozoa (epididymal and electroejaculated) depending on glycerol concentration and extender osmolality. Theriogenology 2006;66(5):1165-72.

[18] Martinez-Pastor F, Anel L, Guerra C, Alvarez M, Soler AJ, Garde JJ, et al. Seminal plasma improves cryopreservation of Iberian red deer epididymal sperm. Theriogenology 2006;66(8): $1847-56$

[19] Fernandez-Santos MR, Esteso MC, Montoro V, Soler AJ, Garde JJ. Influence of various permeating cryoprotectants on freez- ability of Iberian red deer (Cervus elaphus hispanicus) epididymal spermatozoa: effects of concentration and temperature of addition. J Androl 2006;27(6):734-45.

[20] Fernandez-Santos M, Esteso M, Montoro V, Soler A, Garde J. Cryopreservation of Iberian red deer (Cervus elaphus hispanicus) epididymal spermatozoa: effects of egg yolk, glycerol and cooling rate. Theriogenology 2006;66(8):1931-42.

[21] Fernández-Santos M, Esteso M, Soler A, Montoro V, Garde J. Effects of egg yolk and cooling rate on the survival of refrigerated red deer (Cervus elaphus hispanicus) epididymal spermatozoa. Reprod Domest Anim 2006;41(2):114-8.

[22] Fernandez-Santos MR, Martinez-Pastor F, Garcia-Macias V, Esteso MC, Soler AJ, de Paz P, et al. Extender osmolality and sugar supplementation exert a complex effect on the cryopreservation of Iberian red deer (Cervus elaphus hispanicus) epididymal spermatozoa. Theriogenology 2007;67(4):73853.

[23] Soler AJ, Garcia AJ, Fernandez-Santos MR, Esteso MC, Garde $\mathrm{JJ}$. Effects of thawing procedure on postthawed in vitro viability and in vivo fertility of red deer epididymal spermatozoa cryopreserved at -196 degrees C. J Androl 2003;24(5):746-56.

[24] Soler AJ, Esteso MC, Fernandez-Santos MR, Garde JJ. Characteristics of Iberian red deer (Cervus elaphus hispanicus) spermatozoa cryopreserved after storage at 5 degrees $\mathrm{C}$ in the epididymis for several days. Theriogenology 2005;64(7):150317.

[25] Soler AJ, Astore V, Sestelo A, Rivolta M, Jacome LN, Garde JJ. Effect of thawing procedure on cryosurvival of deer spermatozoa: work in progress. Theriogenology 2003;60(3):511-20.

[26] Haigh J, Barth A, Bowman P. An evaluation of extenders for wapiti, Cervus elaphus, semen. J Zoo Anim Med 1986;17:12936.

[27] Veldhuizen F. Studies on cryopreservation of semen of farmed red deer Cervus elaphus and fallow deer Dama dama. Ph.D. thesis, Lincoln University, New Zealand; 1994.

[28] Gizejewski Z, Snochowski M, Mayntz M. Fractions of the semen of red deer (Cervus elaphus) - their occurrence and characteristics in different periods of season. Pol J Vet Sci 2003;6(3):219 23.

[29] McBee LE, Cotterill OJ. High temperature storage of spray-dried egg white. 3. Thermal resistance of Salmonella oranienburg. Poult Sci 1971;50(2):452-8.

[30] Garde JJ, Soler AJ, Cassinello J, Crespo C, Malo AF, Espeso G, et al. Sperm cryopreservation in three species of endangered gazelles (Gazella cuvieri, G. dama mhorr, and G. dorcas neglecta). Biol Reprod 2003;69(2):602-11.

[31] Gil J, Rodriguez-Irazoqui M, Lundeheim N, Soderquist L, Rodriguez-Martinez H. Fertility of ram semen frozen in bioexcell and used for cervical artificial insemination. Theriogenology 2003;59(5-6):1157-70.

[32] Moussa M, Marinet V, Trimeche A, Tainturier D, Anton M. Low density lipoproteins extracted from hen egg yolk by an easy method: cryoprotective effect on frozen-thawed bull semen. Theriogenology 2002;57(6):1695-706.

[33] Mortimer D, Serres C, Mortimer ST, Jouannet P. Influence of image sampling frequency on the perceived movement characteristics of progressively motile human spermatozoa. Gamete Res 1988;20(3):313-27.

[34] R Development Core Team. R: a language and environment for statistical computing, Vienna, Austria: R Foundation for Statistical Computing; 2007. ISBN: 3-900051-07-0. http://www.Rproject.org. 
[35] Soler AJ, Garde JJ. Relationship between the characteristics of epididymal red deer spermatozoa and penetrability into zonafree hamster ova. J Androl 2003;24(3):393-400.

[36] Haigh J, Dradjat A, English A. Comparison of two extenders for the cryopreservation of chital (Axis axis) semen. J Zoo Wildl Med 1993;24:454-8.

[37] Zomborszky Z, Nagy S, Nánássy L, Szabari M, Bodó S. Experiences in deer sperm cryopreservation under practical conditions —a pilot study. Anim Reprod Sci 2005;90(1-2):185-90.

[38] Esteso MC, Fernandez-Santos MR, Soler AJ, Garde JJ. Head dimensions of cryopreserved red deer spermatozoa are affected by thawing procedure. Cryo Letters 2003;24(4):261-8.

[39] de Ruigh L, Bosch JC, Brus MC, Landman B, Merton JS. Ways to improve the biosecurity of bovine semen. Reprod Domest Anim 2006;41(4):268-74.

[40] Maxwell WMC, Parrilla I, Caballero I, Garcia E, Roca J, Martinez EA, et al. Retained functional integrity of bull spermatozoa after double freezing and thawing using PureSperm density gradient centrifugation. Reprod Domest Anim 2007; 42(5):489-94.

[41] Muino R, Fernandez M, Pena AI. Post-thaw survival and longevity of bull spermatozoa frozen with an egg yolk-based or two egg yolk-free extenders after an equilibration period of $18 \mathrm{~h}$. Reprod Domest Anim 2007;42(3):305-11.

[42] Fukui Y, Kohno H, Togari T, Hiwasa M, Okabe K. Fertility after artificial insemination using a soybean-based semen extender (AndroMed) in sheep. J Reprod Dev.

[43] Bergeron A, Manjunath P. New insights towards understanding the mechanisms of sperm protection by egg yolk and milk. Mol Reprod Dev 2006;73(10):1338-44.

[44] Gizejewski Z. Effect of season on characteristics of red deer Cervus elaphus L. semen collected using modified artificial vagina. Reprod Biol 2004;4(1):51-66.

[45] Nunes JF, Corteel JM, Combarnous Y, Baril G. Role of seminal plasma in the in vitro survival of goat sperm. Reprod Nutr Dev 1982;22(4):611-20.
[46] La Falci V, Tortorella H, Rodrigues J, Brandelli A. Seasonal variation of goat seminal plasma proteins. Theriogenology 2002;57(3):1035-48.

[47] Cardozo JA, Fernandez-Juan M, Forcada F, Abecia A, MuinoBlanco T, Cebrian-Perez JA. Monthly variations in ovine seminal plasma proteins analyzed by two-dimensional polyacrylamide gel electrophoresis. Theriogenology 2006;66(4):841-50.

[48] Audige L, Wilson P, Morris R. Reproductive performance of farmed red deer (Cervus elaphus) in New Zealand. I. descriptive data. Anim Reprod Sci 1999;55(2):127-41.

[49] Garde JJ, Del Olmo A, Soler AJ, Espeso G, Gomendio M, Roldan E. Effect of egg yolk, cryoprotectant, and various sugars on semen cryopreservation in endangered cuvier's gazelle (Gazella cuvieri). Anim Reprod Sci doi:10.1016/j.anireprosci.2007.09.010.

[50] Heideman PD. Top-down approaches to the study of natural variation in complex physiological pathways using the whitefooted mouse (Peromyscus leucopus) as a model. ILAR J 2004;45(1):4-13.

[51] Loomis PR, Graham JK. Commercial semen freezing: Individual male variation in cryosurvival and the response of stallion sperm to customized freezing protocols. Anim Reprod Sci 2008;105(12):119-28. www.sciencedirect.com/science/article/B6T434R715WW-6/2/3e8a12bb4cdc2058044143d8a2f274c7.

[52] Martínez AF, Martínez-Pastor F, Álvarez M, Fernández-Santos MR, Esteso MC, de Paz P, Anel L. Sperm parameters on Iberian red deer: Electroejaculation and post-mortem collection. Theriogenology doi:10.1016/j.theriogenology.2008.04.001.

[53] Fernandez-Santos MR, Esteso MC, Soler AJ, Montoro V, Garde JJ. The effects of different cryoprotectants and the temperature of addition on the survival of red deer epididymal spermatozoa. Cryo Letters 2005;26(1):25-32.

[54] Martinez-Pastor F, Diaz-Corujo A, Anel E, Herraez P, Anel L, de Paz P. Post mortem time and season alter subpopulation characteristics of Iberian red deer epididymal sperm. Theriogenology 2005;64(4):958-74. 